\title{
KNOWLEDGE, ATTITUDE AND PRACTICES SURVEY ON AVIAN INFLUENZA IN THREE DISTRICTS OF BANGLADESH
}

\author{
S. K. Sarker ${ }^{1}$, S. M. M. R. Sumon ${ }^{3}$, M. A. H. N. A Khan ${ }^{2}$ and M. T. Islam ${ }^{1 *}$ \\ ${ }^{1}$ Department of Medicine, ${ }^{2}$ Department of Pathology, Faculty of Veterinary Science, Bangladesh Agricultural \\ University, Mymensingh-2202, Bangladesh; ${ }^{3}$ Department of Medicine, Faculty of Veterinary Medicine and \\ Animal Science, Bangabandhu Sheikh Mujibur Rahman Agricultural University, Gazipur, Bangladesh
}

\begin{abstract}
Avian influenza (AI) could have potential public health threat in Bangladesh. The present study aimed to acquire the information on knowledge, attitude and practices (KAP) of the backyard and commercial poultry farmers, farm workers, live bird seller, live bird market workers and transporters, and identify risk factors related to KAP on poultry rearing and other practices pertaining to AI. This survey was conducted in Gazipur, Mymensingh (AI reported districts) and Habiganj (AI nonaffected district). A total number of 600 respondents were interviewed with a structured questionnaire prepared in Magpi and data were collected using Android smart phone. More than half (55.7\%) respondents had heard about AI and mass media was the predominant source of information (46.7\%). A total of $60.2 \%$ of the respondents agreed that AI is a serious and $65.7 \%$ agreed that it is a preventable disease. Regarding hygienic practices 32\% respondents use disinfectant regularly and $73.2 \%$ respondents wash hands after handling of birds. Protective measures such as the use of gloves and mask were not used by $93 \%$ respondents. The results indicated a higher knowledge score among the respondents of affected areas than those of nonaffected areas. Regarding the attitude score, it was revealed that $54.5 \%$ of respondents had good attitude scores towards AI. That is understood that the majority of respondents had positive attitude towards AI. Regarding the practices score, it revealed that $49.5 \%$ had practice at a satisfactory level. The practice score was more satisfactory among the respondents of affected areas than those of non-affected areas. The information on levels of knowledge, attitude and practices regarding AI gathered in this study could provide scientific support to assist the Bangladesh government in developing strategies and health education campaigns to prevent transmission of the AI virus among the general population.
\end{abstract}

Keywords: Avian influenza, knowledge, attitude, practices, cross-sectional study

\section{INTRODUCTION}

Avian Influenza (AI) popularly known as 'Bird Flu, caused by Type A influenza virus. Influenza A viruses are the only orthomyxo viruses known to naturally infect birds, and can infect several species of food producing birds (chickens, ducks, turkeys, quails, guinea fowl etc.), as well as pet birds and wild birds with some strains (e.g. Influenza A) resulting in high mortality rates. At present, $16 \mathrm{H}$ subtypes (H1-H16) and $9 \mathrm{~N}$ subtypes (N1N9) have been recognized (Echeverry and Rodas, 2011).

To date, naturally occurring highly pathogenic avian influenza A (HPAI) viruses that produce acute clinical disease in chickens, ducks, turkeys and other birds of economic importance have been associated only with the $\mathrm{H} 5$ and $\mathrm{H} 7$ subtypes. Most viruses of the $\mathrm{H} 5$ and $\mathrm{H} 7$ subtype isolated from birds have been of low pathogenic for poultry. As there is a risk of $\mathrm{H} 5$ or $\mathrm{H} 7$ virus of low virulence becoming virulent by mutation, all $\mathrm{H} 5$ and $\mathrm{H} 7$ viruses have been designated as Notifiable Avian Influenza (NAI) viruses. The virus has also been isolated from mammalian species including humans, rats and mice, weasels and ferrets, pigs, cats, tigers and dogs (OIE, 2013a).The first known direct avian to human transmission of influenza A (subtype H5N1) viruses was reported during an outbreak in Hong Kong in 1997 and exposure to infected poultry was identified as the probable route of transmission. Since then, outbreaks of the H5N1 highly pathogenic Avian Influenza strain have been identified in birds, wild and domestic poultry, in several countries, particularly in Vietnam, Indonesia, Thailand, China, Cambodia and more recently, in Turkey and Iraq (Giuseppe et al., 2008).

From 2003 to 3 March 2015, a total number of 784 laboratory-confirmed human cases with Avian Influenza A (H5N1) virus infection have been officially reported to WHO from 16 affected countries, among these 429 died

*Corresponding author's e-mail: taohid@bau.edu.bd

Copyright () 2016 Bangladesh Society for Veterinary Medicine

All rights reserved 0348/2016 


\section{S. K. Sarker and others}

(WHO, 2015). Avian Influenza A/H5N1 is considered as public health potential risk. If a pandemic human influenza occurred by $\mathrm{H} 5 \mathrm{~N} 1$ then it is assumed that millions of people will die (Thomas and Noppenberger, 2007).

Officially Bangladesh was declared affected by HPAI H5N1 virus on 22 March 2007. Till 2013, a total of 549 outbreaks were recorded in 51 out of 64 districts and most outbreaks were in commercial poultry farms (OIE, 2013b). And around 2.3 million birds had been destroyed during this period (OIE, 2013b). Up to March 2013, a total of 6 human cases of Avian Influenza have been reported from Bangladesh. The first human case of influenza A/ H5N1 was recognized in Bangladesh and WHO was notified by Bangladesh Government on 22 May, 2008. The first human who infected was 15-month-old boy; his mother touched him after washing an infected poultry (Institute for Epidemiology Disease Control and Research (IEDCR), Ministry of Health and Family Welfare, Government of the People's Republic of Bangladesh).However, no human fatal cases with HPAI H5N1 have so far been reported in Bangladesh (FAO's initiative on HPAI control in Bangladesh, 2012). Bangladesh is now at Pandemic alert period i.e. in Phase 3.The persons who slaughter, farm, rear, transport, sell and who are closely related with poultry are considered as high risk areas (Xiang et al., 2010). The presence in the household of dead or sick poultry acts as a risk factor (Fielding et al., 2005). For the purpose of controlling AI a sound communication channel is a burning question to set up. But the effective design and delivery of AI prevention and included messages depend on the acquisition of knowledge on the overall human/avian interaction especially in rural communities.

The KAP is a representative survey conducted on a particular population to identify the knowledge (K), attitudes (A) and practices (P) of a population on a specific topic. In most of the KAP studies, data are gathered orally by an interviewer who uses a structured, standardized questionnaire. Some research works were carried out to acquire information on knowledge, attitudes, and practices regarding AI in Bangladesh. The number of respondents who heard about AI varied from $40 \%$ to $85 \%$ in Bangladesh (Sarker et al., 2009; Sultana et al., 2011). Mass media was the source of information for $45 \%$ in urban and $36 \%$ in periurbanlive bird markets (LBMs). Only $23 \%$ and $11 \%$ respondents from urban and periurban area used facemask respectively, and $17 \%$ respondents for urban areas use disinfectant spray (Sarker et al., 2009).

However, the other people especially commercial poultry farmers, farm workers, transporters are needed to interview to know the level of knowledge, their attitude and practices they performed with regard to AI and to identify the risk factors relating AI, so that an effective communication channel can be set up to control AI. Therefore, the present research work was undertaken i) to acquire information about the understanding of respondent knowledge, attitude and practices (KAP) on poultry rearing and other practices pertaining to AI both in AI infected and non-infected areas, and ii) to identify the risk factors related to KAP on poultry rearing and other practices pertaining to AI.

\section{MATERIALS AND METHODS}

\section{Study area, population and duration}

There were 51 districts in Bangladesh reported to be affected with AI and 13 districts reported non-affected (OIE, 2013b). The study was conducted in three districts, two of which were randomly selected from affected districts and one from non-affected districts. The affected districts were Gazipur and Mymensingh and nonaffected district was Habiganj. Two affected upazilas Sreepur and Mymensingh Sadar were selected randomly from Gazipur and Mymensingh districts respectively. Two non-affected upazilas Habiganj Sadar and Chunarughat were selected from Habiganj District. Three hundred respondents were interviewed from affected upazilas and three hundred respondents from non-affected upazilas; 300 interviewed having 150 from each upazila (Table 1). Respondents were commercial poultry farmers, backyard farmers, farm workers, live bird market workers, live bird seller and poultry transporters. The study was conducted during January to May, 2014. 
Knowledge, attitude and practices survey on avian influenza

Table 1. Details of study areas with number of respondents

\begin{tabular}{|c|c|c|c|c|c|}
\hline \multirow[t]{3}{*}{ Types of respondents } & \multicolumn{2}{|l|}{ Affected districts } & \multicolumn{2}{|l|}{ Non-affected district } & \multirow[t]{3}{*}{ Total } \\
\hline & Gazipur & Mymensingh & Habigonj & & \\
\hline & Sreepur upazila & Sadar upazila & Chunarughat upazila & Sadar upazila & \\
\hline Commercial poultry farmers & 27 & 24 & 30 & 18 & 99 \\
\hline Backyard farmers* & 32 & 63 & 77 & 77 & 249 \\
\hline Farm workers & 41 & 14 & 10 & 06 & 71 \\
\hline Live bird market workers & 27 & 21 & 07 & 17 & 72 \\
\hline Live bird seller & 07 & 24 & 23 & 17 & 71 \\
\hline Poultry transporters & 16 & 04 & 03 & 15 & 38 \\
\hline Total & 150 & 150 & 150 & 150 & 600 \\
\hline
\end{tabular}

*Backyard farmers are those who rear poultry in their houses for not only food purposes but also for commercial purpose in a small scale.

\section{Data collection}

A cross sectional study was conducted with a structured questionnaire prepared in Magpi (www.magpi.com) and data were collected using android smart phone. Respondents were interviewed in their working place. The questionnaire was carefully explained so that they could answer the questions properly and easily. The questionnaire contained 54 items which included socio-demographic data, questions regarding knowledge, attitude and practices regarding avian influenza. Most of the questions were closed-ended. Direct observations were also made to compare with respondents' answers and thus the respondents were cross-questioned to have the real fact.

\section{Socio-demographic data}

In this part, 8 questions were included. They questions were about address, age, sex, education, occupation etc. The ages of informants ranged from 18 to above 45. The ages of all respondents arranged into four categories namely 18-25 years, 26-35 years, and 36-45 years and above 45 years.

\section{Knowledge of AI}

There were 10 questions in this section. The knowledge section comprised of questions about knowledge on AI: source of AI, species which are affected by AI, method of transmission to humans and to poultry, symptoms both in poultry and human and contagious nature of AI. The questions were scored with 1 for correct and 0 for incorrect answer and thus the total scores was 15. Levels of knowledge score were categorized as $\leq 5,6-10$ and $\geq 11$.

\section{Attitudes towards AI}

This section contained 15 questions such as it kills both human and bird, would you accept AI vaccine, would take you treatment, seriousness of AI, whether preventable or not, eating behaviors etc. Each item contained binary choices: "agree" and "disagree" or "yes" and "no". A score of 1 was given for appropriate attitude and 0 for inappropriate attitude. The total scores were 15 . The levels of attitude scores were grouped into three categories as $\leq 5 ; 6-10$ and $\geq 11$.

\section{Practices related to AI}

This section contained 24 items. These included using protective clothes, gloves, washing hands, instruments, disinfection of poultry place, reporting to veterinary personnel, handling of dead poultry, separation of poultry from other animals etc. The scoring method was applied for each item: 1 point was given for "appropriate practice" and 0 for "inappropriate" practice. The total score was 23 . Practice scores were categorized as $\leq 8,9-$ 16 and $\geq 17$. 


\section{S. K. Sarker and others}

\section{Data analysis}

Data stored real time in Magpi web server were extracted as MS Access file and read into Epi-Info software versions 3.5.3(CDC, Atlanta). Proportions of the respondents in terms of knowledge, attitude and practice for affected and non-infected areas were compared using chi-square test. The multiple linear regression models was used to analyze possible influencing factors associated with respondents' AI knowledge and attitudes. The comparison of KAP scores between affected and non-affected areas was done using Mann-Whitney test by using SPSS v.20. For all analyses, significance levels were two-tailed, and a P-value of $\leq 0.05$ was considered significant.

\section{RESULTS AND DISCUSSION}

\section{Socio-demographic characteristics of the respondents}

A total of 600 people were interviewed, among them $476(79.3 \%)$ were male and $124(20.7 \%)$ were female (Table2). Studying the age ratio, about one fourth (24.5\%) of the respondents was at the age areas of 45 and above and the highest percentage $(29.3 \%)$ of the respondents were aged between 26-35 years (Table2).It was found that $39.8 \%$ of respondents had completed the primary education and $37.5 \%$ respondents had no formal education. The proportion of respondents with no formal educations in the non- affected areas was more than that of affected which included $35.7 \%$ with no formal education in affected areas compared to $39.3 \%$ in non-affected areas. The level of higher education (HSC and above) was more in the non-affected areas $(11.7 \%)$ than the affected areas $(5.7 \%)$. The proportion of respondents reported owning backyard poultry and commercial poultry farm were $41.5 \%$ and $16.5 \%$ respectively, while $11.8 \%, 12 \%, 11.8 \%$ and $6.3 \%$ respondents reported working as farm worker, live bird market worker, live bird seller and transporter, respectively. It was found that $61.3 \%$ and $60.7 \%$ respondents from non-affected and affected upazillas were engaged in rearing of poultry (Table2).

Table 2. Socio-demographic characteristics of study respondents

\begin{tabular}{llll}
\hline Variables & $\begin{array}{l}\text { Affected upazilla } \\
(\mathrm{n}=300) \\
\text { No. }(\%)\end{array}$ & $\begin{array}{l}\text { Non-affected upazilla } \\
(\mathrm{n}=300) \\
\text { No. }(\%)\end{array}$ & $\begin{array}{l}\text { Total } \\
(\mathrm{n}=600) \\
\text { No. }(\%)\end{array}$ \\
\hline Sex & $255(85.0)$ & $221(73.7)$ & $476(79.3)$ \\
$\quad$ Male & $45(15)$ & $79(26.3)$ & $124(20.7)$ \\
$\quad \begin{array}{l}\text { Female } \\
\text { Age (years) }\end{array}$ & $50(16.7)$ & $78(26.0)$ & $128(21.3)$ \\
18-25 & $93(31.0)$ & $83(27.7)$ & $176(29.3)$ \\
$26-35$ & $82(27.3)$ & $67(22.3)$ & $149(24.8)$ \\
36-45 & $75(25.0)$ & $72(24.0)$ & $147(24.5)$ \\
Above 45 & & & $225(37.5)$ \\
Education & $107(35.7)$ & $118(39.3)$ & $239(39.8)$ \\
No formal education & $132(44.0)$ & $107(35.7)$ & $84(14.0)$ \\
Primary & $44(14.7)$ & $40(13.3)$ & $52(8.7)$ \\
SSC & $17(5.7)$ & $35(11.7)$ & \\
HSC and above & & & $249(41.5)$ \\
& & $154(51.3)$ & $99(16.5)$ \\
Occupation & $95(31.7)$ & $48(16.0)$ & $71(11.8)$ \\
$\quad$ Backyard poultry farmer & $51(17.0)$ & $16(5.3)$ & $72(12.0)$ \\
Commercial poultry farmer & $55(18.3)$ & $24(8.0)$ & $71(11.8)$ \\
Farm worker & $48(16.0)$ & $40(13.3)$ & $38(6.3)$ \\
Live bird market worker & $31(10.3)$ & $18(6.0)$ & $366(61.0)$ \\
Live bird seller & $20(6.7)$ & $184(61.3)$ & \\
Transporter & $182(60.7)$ & &
\end{tabular}




\section{Knowledge about AI}

Knowledge, attitude and practices survey on avian influenza

It was revealed that $76.7 \%$ respondents from $\mathrm{AI}$ affected areas knew about AI while only $34.7 \%$ of respondents from non-affected areas knew about $\mathrm{AI}(\mathrm{P} \leq 0.001)$. The major source of information identified in this study was mass media. About $47 \%$ respondents had heard about AI from mass media (Table 3).A minor percentage of respondents $(24.3 \%)$ from both affected and non-affected areas knew about the source of infection of AI to poultry. However the percentage was significantly higher (38.3\%)in affected areas than those of non-affected areas $(10.3 \%)$. Similar finding was observed about the source of infection of AI to human. Only $29.5 \%$ of the respondents from both areas knew about the source of infection of AI to human (Table3).A majority of respondents $(44.3 \%)$ did not know about the species at risk of AI infection. However around 51\% respondents from affected areas answered that chickens and ducks are the species at risk of AI infection (Table 3).Among $52 \%$ interviewed respondents who mentioned that $\mathrm{AI}$ is a threat to human, $70 \%$ were from affected areas and $34 \%$ from non-affected areas $(\mathrm{P}<0.001)$. Similar results were found when the respondents were asked whether $\mathrm{AI}$ is contagious or not, around 70\% respondents from affected areas knew that $\mathrm{AI}$ is a contagious disease while it was only $34 \%$ from non-affected areas $(\mathrm{P}<0.001)$. Forty-one percent of the interviewed respondents knew the mode of transmission to poultry $(61.7 \%$ from affected areas and $21 \%$ from non-affected areas; $\mathrm{P}<0.001)$ (Table 3). Around $28 \%$ of the interviewed respondents had knowledge of the symptoms of AI in poultry while it was found that only $7.7 \%$ interviewed respondents had knowledge on symptom of AI inhuman.

Table 3. Knowledge of study participants related to avian influenza

\begin{tabular}{|c|c|c|c|c|}
\hline Variables & $\begin{array}{l}\text { Affected areas } \\
(\mathrm{n}=300) \text { No. }(\%)\end{array}$ & $\begin{array}{l}\text { Non-affected areas } \\
(\mathrm{n}=300) \text { No. }(\%)\end{array}$ & $\begin{array}{l}\text { Total } \\
\text { No. }(\%)\end{array}$ & P-value \\
\hline Heard about AI & $230(76.7)$ & $104(34.7)$ & $334(55.7)$ & $<0.001$ \\
\hline \multicolumn{5}{|l|}{ Source of information } \\
\hline Family and neighbour & $26(11.3)$ & $7(6.7)$ & $33(9.9)$ & \multirow{4}{*}{$<0.001$} \\
\hline Family and neighbour and vet personnel & $37(16.1)$ & $13(12.5)$ & $50(15.0)$ & \\
\hline Mass media & $86(37.4)$ & $70(67.3)$ & $156(46.7)$ & \\
\hline $\begin{array}{l}\text { Mass media and family and neighbour and vet } \\
\text { personnel }\end{array}$ & $81(35.2)$ & $14(13.5)$ & $95(28.4)$ & \\
\hline Knowledge on source of infection to poultry & $115(38.3)$ & $31(10.3)$ & $146(24.3)$ & $<0.001$ \\
\hline Knowledge on source of infection to human & $144(48.0)$ & $33(11.0)$ & $177(29.5)$ & $<0.001$ \\
\hline \multicolumn{5}{|l|}{ Knowledge of species at risk of AI infection } \\
\hline Chicken & $29(9.7)$ & $19(6.3)$ & $48(8.0)$ & \multirow{5}{*}{$<0.001$} \\
\hline Chicken and duck & $152(50.7)$ & $76(25.3)$ & $228(38.0)$ & \\
\hline Chicken, duck, quail and pigeon & $35(11.7)$ & $5(1.7)$ & $40(6.7)$ & \\
\hline Chicken, duck, quail, pigeon, crow and geese & $14(4.7)$ & $4(1.3)$ & $18(3.0)$ & \\
\hline Do not know & $70(23.3)$ & $196(65.3)$ & $266(44.3)$ & \\
\hline Knowledge of mode of transmission to poultry & $185(61.7)$ & $63(21.0)$ & $248(41.3)$ & $<0.001$ \\
\hline Knowledge on symptom of AI on poultry & $133(44.3)$ & $32(10.7)$ & $165(27.5)$ & $<0.001$ \\
\hline Knowledge on symptom of AI on human & $41(13.7)$ & $5(1.7)$ & $46(7.7)$ & $<0.001$ \\
\hline Knowledge on treatment of AI & $66(22.0)$ & $14(4.7)$ & $80(13.3)$ & $<0.001$ \\
\hline Is it threat to human? & $210(70.0)$ & $102(34.0)$ & $312(52.0)$ & $<0.001$ \\
\hline Is it contagious? & $209(69.7)$ & $102(34.0)$ & $311(51.8)$ & $<0.001$ \\
\hline
\end{tabular}

\section{Attitude towards AI}

It was found that $60.2 \%$ respondents believed that $\mathrm{AI}$ is a serious disease, $40.3 \%$ believed that both birds and human could die from it and regarding disease threats, $55 \%$ of the respondents agreed that AI is threatening to everybody. The respondents those perceived that AI could be prevented by hand washing with water and soap was $64.7 \%$ and by using personnel protection equipment and by removal of all home bird cages were $65.2 \%$ and $65 \%$ respectively. A total of $59.3 \%$ respondents mentioned that they would become scared after getting infection and $38.5 \%$ respondents said that they should stay away from sick bird to protect themselves (53\% from affected areas and $24 \%$ from non-affected areas $(\mathrm{P}<0.001)$ (Table 4$)$. 


\section{S. K. Sarker and others}

The cent percent respondents from both affected and non-affected areas mentioned that they would take treatment and $74.8 \%$ respondents said that they would go to doctor to seek treatment, while only $25.2 \%$ respondents mentioned that they would seek treatment from others (Quack or Pharmaceutical shop owner). Regarding vaccination $62 \%$ respondents mentioned that they would accept AI vaccine (66\% from affected areas and 58\% from non-affected areas; $\mathrm{P}=0.040$ ) (Table4).The proportion of respondents those agreed with eating, selling and slaughtering sick birds were $12.5 \%, 6.3 \%$ and $4.8 \%$ respectively (Table 4).However, no significant differences were found in these attitudes between the affected and non-affected areas.

Table 4. Attitude of study participants related to avian influenza

\begin{tabular}{|c|c|c|c|c|}
\hline Variables & $\begin{array}{l}\text { Affected areas } \\
(\mathrm{n}=300) \\
\text { No. }(\%)\end{array}$ & $\begin{array}{l}\text { Non-affected areas } \\
(\mathrm{n}=300) \\
\text { No. }(\%)\end{array}$ & $\begin{array}{l}\text { Total } \\
(\mathrm{n}=600) \\
\text { No. }(\%)\end{array}$ & P-value \\
\hline It kill both birds and human & $182(60.7)$ & $60(20.0)$ & $242(40.3)$ & $<0.001$ \\
\hline $\begin{array}{l}\text { Would you take treatment if become } \\
\text { affected? }\end{array}$ & $300(100)$ & $300(100)$ & $600(100)$ & - \\
\hline \multicolumn{5}{|l|}{ Would you take treatment by whom? } \\
\hline Doctor & $227(75.7)$ & $222(74.0)$ & $449(74.8)$ & 0.640 \\
\hline Others* & $73(24.3)$ & $78(26.0)$ & $151(25.2)$ & \\
\hline Would you accept AI vaccine? & $198(66.0)$ & $174(58.0)$ & $372(62.0)$ & 0.040 \\
\hline Become scared after getting infection & $179(59.7)$ & $177(59.0)$ & $356(59.3)$ & 0.870 \\
\hline Stay away from sick bird & $159(53.0)$ & $72(24.0)$ & $231(38.5)$ & $<0.001$ \\
\hline Agree that $\mathrm{AI}$ is a serious disease & $229(76.3)$ & $132(44.0)$ & $361(60.2)$ & $<0.001$ \\
\hline $\begin{array}{l}\text { Agree that } \mathrm{AI} \text { is threatening to } \\
\text { everybody }\end{array}$ & 209 (69.7) & $121(40.3)$ & $330(55.0$ & $<0.001$ \\
\hline AI could be prevented & $216(72.0)$ & $178(59.3)$ & $394(65.7)$ & 0.001 \\
\hline Eating sick bird meat & $44(14.7)$ & $31(10.3)$ & $75(12.5)$ & 1.110 \\
\hline Selling of sick poultry & $16(5.3)$ & $22(7.3)$ & $38(6.3)$ & 0.310 \\
\hline Slaughtering of sick poultry & $11(3.7)$ & $18(6.0)$ & $29(4.8)$ & 0.180 \\
\hline $\begin{array}{l}\text { AI could be prevented by hand } \\
\text { washing with water and soap }\end{array}$ & $213(71.0)$ & $175(58.3)$ & $388(64.7)$ & 0.001 \\
\hline $\begin{array}{l}\text { AI could be prevented by using } \\
\text { personal protection equipment }\end{array}$ & $216(72.0)$ & $175(58.3)$ & $391(65.2)$ & $<0.001$ \\
\hline $\begin{array}{l}\text { AI could be prevented by removal of } \\
\text { all home bird cages }\end{array}$ & $215(71.7)$ & $175(58.3)$ & $390(65.0)$ & $<0.001$ \\
\hline
\end{tabular}

*Others mean quack or pharmaceutical shop and who are not registered authority.

\section{Practice of study participants related to AI}

It was remarkable that the highest percentages of respondents those take protective measures were found in AI affected areas. Overall 13\%, 19\%, 15.3\% and 13.7\% of the respondents from affected areas mentioned that they use protective clothes, keep separate foot wear, use clean clothes, and use gloves respectively (Table 5).A good proportion of the respondents $(73.2 \%)$ washed their hands after handling the dead body of poultry $(67.7 \%$ from affected areas and $78.7 \%$ in non-affected areas; $\mathrm{P}=0.002$ ). And $87.5 \%$ respondents practiced cleaning instrument after slaughtering of birds (Table 5).A total $17.8 \%$ of the respondents reported that they eat meat of birds. The belief is that when meat is well cooked then all the germs are killed. It was found that $83.3 \%$ of respondents practiced poultry slaughtering at their homes (71\% from affected areas and $95.7 \%$ from non-affected areas, $\mathrm{P}<$ 0.001 ). Eating raw or half cooked eggs and meat remains an unusual practice; only $1.3 \%$ respondents reported practicing it (Table 5). 
It was mentioned by the respondents that $48 \%$ and $13.8 \%$ of them threw offal or dead poultry in the bushes or nearest body of water, respectively while $38.2 \%$ respondents buried the dead poultry under soil before hearing about bird flu. And after hearing about bird flu 57.2\% respondents reported that they would bury the carcass under soil (Table 5).As the human especially children are at risk of AI infection so questions regarding to avoid of contact with poultry were asked. A total of $27.2 \%$ respondents mentioned they avoid themselves away from poultry. Around 37\% from AI infected areas and 19\% from AI non-affected areas mentioned that they would report to vet personnel about sudden death of poultry $(\mathrm{P}<0.001)$ (Table 5).

Table 5. Practice of study participants related to avian influenza

\begin{tabular}{|c|c|c|c|c|}
\hline Variables & $\begin{array}{l}\text { Affected areas } \\
(\mathrm{n}=300) \\
\text { No. }(\%)\end{array}$ & $\begin{array}{l}\text { Non-affected areas } \\
(\mathrm{n}=300) \\
\text { No. }(\%)\end{array}$ & $\begin{array}{l}\text { Total } \\
(\mathrm{N}=600) \\
\text { No. }(\%) \\
\end{array}$ & P-value \\
\hline Using protective clothes & $39(13.0)$ & $4(1.3)$ & $43(7.2)$ & $<0.001$ \\
\hline Wear clean clothes & $46(15.3)$ & $19(6.3)$ & $65(10.8)$ & $<0.001$ \\
\hline Wash the clothes used at farm & $74(24.7)$ & $40(13.3)$ & $114(19.0)$ & $<0.001$ \\
\hline Keep separate foot wear & $57(19.0)$ & $25(8.3)$ & $82(13.7)$ & $<0.001$ \\
\hline Keep new chicks separate from old chicks & $231(77.0)$ & $262(87.3)$ & $493(82.2)$ & $<0.001$ \\
\hline Keep poultry separate from other animals & $287(95.7)$ & $292(97.3)$ & $579(96.5)$ & 0.270 \\
\hline Prevent contact of poultry from wild birds & $208(69.3)$ & $144(48.0)$ & $352(58.7)$ & $<0.001$ \\
\hline Keep children away from poultry & $219(73.0)$ & $159(53.0)$ & $378(63.0)$ & $<0.001$ \\
\hline Restrict the entry into farm & $124(41.3)$ & $68(22.7)$ & $192(32.0)$ & $<0.001$ \\
\hline Use of disinfectant regularly & $143(47.7)$ & $63(21.0)$ & $206(34.3)$ & $<0.001$ \\
\hline Slaughter and sell of sick poultry & $183(61.0)$ & $207(69.0)$ & $390(65.0)$ & $<0.001$ \\
\hline Clean instrument after slaughtering & $255(85.0)$ & $270(90.0)$ & $525(87.5)$ & $<0.001$ \\
\hline Wash hand after handling of birds & $203(67.7)$ & $236(78.7)$ & $439(73.2)$ & $<0.001$ \\
\hline Eat meat of sick birds & $78(26.0)$ & $29(9.7)$ & $107(17.8)$ & $<0.001$ \\
\hline Eat raw or half cooked egg or meat & $6(2.0)$ & $2(0.7)$ & $8(1.3)$ & 0.150 \\
\hline Handling of dead poultry & $206(68.7)$ & $233(77.7)$ & $439(73.2)$ & 0.010 \\
\hline $\begin{array}{l}\text { Throwing and burying offal / carcasses before } \\
\text { hearing about "bird flu" }\end{array}$ & & & & \\
\hline Throwing in the bushes & $117(39.0)$ & $171(57.0)$ & $288(48.0)$ & \\
\hline Throwing in nearest water body & $40(13.3)$ & $43(14.3)$ & $83(13.8)$ & $<0.001$ \\
\hline Burying under soil & $143(47.7)$ & $86(28.7)$ & $229(38.2)$ & \\
\hline \multicolumn{5}{|l|}{$\begin{array}{l}\text { Throwing and burying offal / carcasses after } \\
\text { hearing about "bird flu" }\end{array}$} \\
\hline Throwing in the bushes & $74(24.7)$ & $127(42.3)$ & $201(33.5)$ & \\
\hline Throwing in nearest water body & $25(8.3)$ & $31(10.3)$ & $56(9.3)$ & $<0.001$ \\
\hline Burying under soil & $201(67.0)$ & $142(47.3)$ & $343(57.2)$ & \\
\hline Disinfectant the place of poultry & $252(84.0)$ & $159(53.0)$ & $411(68.5)$ & $<0.001$ \\
\hline $\begin{array}{l}\text { Report to vet personnel about massive death of } \\
\text { poultry }\end{array}$ & $110(36.7)$ & $56(18.7)$ & $166(27.7)$ & $<0.001$ \\
\hline Use gloves & $41(13.7)$ & $1(0.3)$ & $42(7.0)$ & $<0.001$ \\
\hline Slaughter poultry at home & $213(71.0)$ & 287 (95.7) & $500(83.3)$ & $<0.001$ \\
\hline Avoid contact with sick birds & $100(33.3)$ & $63(21.0)$ & $163(27.2)$ & $<0.001$ \\
\hline
\end{tabular}

\section{Factors associated with KAP following outbreak of AI}

Considering knowledge score, $57.5 \%$ of respondents had a low level of knowledge. The results also indicated a higher knowledge score among the respondents of affected areas than those of non-affected areas (Table $6 \& 7$ ). 


\section{S. K. Sarker and others}

Table 6. Proportion of respondents according to KAP levels of avian influenza

\begin{tabular}{|c|c|c|c|}
\hline KAP levels & $\begin{array}{l}\text { Affected areas } \\
(\mathrm{n}=300) \text { No. }(\%)\end{array}$ & $\begin{array}{l}\text { Non-affected areas } \\
(\mathrm{n}=300) \text { No. }(\%)\end{array}$ & $\begin{array}{l}\text { Total } \\
(\mathrm{N}=600) \text { No. }(\%)\end{array}$ \\
\hline \multicolumn{4}{|c|}{ Knowledge score levels $($ Total scores $=15)$} \\
\hline$\leq 5$ & $110(36.7)$ & $235(78.3)$ & $345(57.5)$ \\
\hline $6-10$ & $147(49.0)$ & $61(20.3)$ & $208(34.7)$ \\
\hline$\geq 11$ & $43(14.3)$ & $4(1.3)$ & $47(7.8)$ \\
\hline \multicolumn{4}{|c|}{ Attitude $($ Total scores $=15)$} \\
\hline$\leq 5$ & $17(5.7)$ & $50(16.7)$ & $67(11.2)$ \\
\hline $6-10$ & $90(30.0)$ & $116(38.7)$ & $206(34.3)$ \\
\hline$\geq 11$ & $193(64.3)$ & $134(44.7)$ & $327(54.5)$ \\
\hline \multicolumn{4}{|c|}{ Practices $($ Total scores $=23)$} \\
\hline$\leq 8$ & $64(21.3)$ & $166(55.3)$ & $230(38.3)$ \\
\hline $9-16$ & $167(55.7)$ & $130(43.3)$ & $297(49.5)$ \\
\hline$\geq 17$ & $69(23.0)$ & $4(1.3)$ & $73(12.2)$ \\
\hline
\end{tabular}

Table 7. Comparison of knowledge, attitude and practices scores between affected and non-affected areas

\begin{tabular}{|c|c|c|c|c|}
\hline KAP score & Median & Range & $\mathrm{Z}^{*}$ & P-value \\
\hline \multicolumn{5}{|l|}{ Knowledge score } \\
\hline Affected areas $(n=300)$ & 7 & $0-15$ & -11.544 & $<0.001$ \\
\hline Non-affected areas $(\mathrm{n}=300)$ & 0 & $0-15$ & & \\
\hline \multicolumn{5}{|l|}{ Attitude score } \\
\hline Affected areas $(n=300)$ & 12 & $2-15$ & -7.406 & $<0.001$ \\
\hline Non-affected areas $(\mathrm{n}=300)$ & 10 & $3-15$ & & \\
\hline \multicolumn{5}{|l|}{ Practice score } \\
\hline Affected areas $(n=300)$ & 12 & $5-22$ & -10.658 & $<0.001$ \\
\hline Non-affected areas $(n=300)$ & 8 & $3-19$ & & \\
\hline
\end{tabular}

*The Z statistic was obtained from the Mann-Whitney test for two independent samples.

Regarding the attitude score, it was revealed that $54.5 \%$ of respondents had good attitude scores towards AI. That is understood that the majority of respondents had positive attitude towards AI. Regarding the practices score, it revealed that the majority of respondents $(49.5 \%)$ had practice at a satisfactory level. The practice score was more satisfactory among the respondents of affected areas than those of non-affected areas.

The results of this study revealed that the knowledge of the study population was moderate related to modes of transmission, symptoms, source, treatment and prevention of HPAI. The study had similar findings with compared to study conducted in China, Thailand, Indonesia, Myanmar and Nepal. Illiteracy is the main factor which hinders the awareness regarding to AI (Giuseppe et al., 2008). The findings about the respondents heard about AI differ from a previous survey conducted in Bangladesh, where $40 \%$ and $10 \%$ respondents from Rajshahi and Netrokona had heard about AI respectively (Sultana et al., 2011). Another study conducted among the live bird market workers in Mymensingh district had better percentage of respondents who had heard about AI; $83 \%$ in urban and $76 \%$ in periurban areas respectively (Sarker et al., 2009), the dissimilarity may be due to the study was conducted in backyard poultry raisers and live bird market workers respectively.

The findings about precautionary measures are dissimilar to findings from a previous study conducted on live bird market workers in Mymensingh district (Sarker et al., 2009). But, that particular study revealed a higher percentage of knowledge about hand washing (57\% urban and $78 \%$ in periurban areas) which is similar to present study. In present study it was observed that most of the live bird market workers do not wash their hands after handling of birds. The present study showed a lower level of proper hygienic practice among the respondents of both areas. Another study conducted in Nepal among butchers showed low compliance with precautionary behavior (Paudel et al., 2013). All implied the practice of precautionary activities in avoiding 
infection by AI virus needs to be strengthened. The present study also showed that about 50\% respondents had moderate practices. Almost similar level of practices was also reported in a study in Myanmar, Afghanistan and Thailand among the high-risk people (MMRD Research Services, Myanmar 2006; (Leslie et al., 2008). A good number $(73 \%)$ of the respondents practiced hand washing after handling birds, $13.7 \%$ used separate foot wear and $7 \%$ of the respondents used gloves. Use of various personal protective equipment (PPE) and sanitation measures are the part of the comprehensive response to prevent and control AI. The main source of infection of human was the contact with infected poultry (WHO, 2013). The most alarming risk factor for AI infection is lack of good practices and it is transmitted to people who are always engaged with poultry (Abbate et al., 2006).

As for safety precaution practices, in present study around $27 \%$ of respondents avoided contact with sick birds. This finding is not corresponding to a KAP study performed in Egypt where $67.6 \%$ of respondents mentioned avoiding contact with sick birds (Ismail and Ahmed, 2010). In the present study 60\% respondents believed that $\mathrm{AI}$ is a serious disease, this finding is not compatible with earlier KAP study performed in Egypt in which 99\% believed that it is a serious disease (Ismail and Ahmed, 2010)but similar to the results of KAP study conducted in Italy (Abbate et al., 2006; Giuseppe et al., 2008). Regarding to seriousness, around 66\% respondents agreed that AI could be prevented which agree with the positive attitude of $79 \%, 53 \%$ and $71 \%$ respondents reported earlier (Fatiregun and Saani, 2008; Giuseppe et al., 2008; Najimi and Golshiri, 2013).

The current study illustrated that around $83 \%$ respondents slaughtered poultry at home which is discordant with the earlier report (Ismail and Ahmed, 2010) in which it was found that 93\% of respondents practice slaughtering poultry at home. Throwing dead poultry in bushes or water body is a common practice revealed in the present study which is in agreement with an inland report in which it has been reported that $85 \%$ respondents threw the offal or carcass either in bushes or nearest water body (Sultana et al., 2011).This study found a statistically significant relationship between knowledge and practices. Proper knowledge helped to create awareness and this leaded to good practices. The main information sources about AI infection for both areas were the mass media. Education played a vital role in getting, understanding and memorizing the information. Increased knowledge and appropriate attitude-practices relating to AI infection were influenced by education, occupation among the study population in an AI affected community, as well as by the awareness of the presence of AI patients in the community.

In conclusion, the results of this study illustrates that, most of the respondents had no detailed knowledge of AI, had a great perceived risk of experiencing avian influenza, and had a low level of practices and protective behavior. These findings indicate that tailored educational programme is needed to correct these deficiencies and measuring their effectiveness on improving the knowledge and practice should have the priority to encourage the population to take a more active role. Nevertheless, it is important to consider that dissemination and widespread adoption of preventive measures require education. It was observed that most of the respondents had interest in learning more about avian influenza. Designing and implementing avian influenza educational programs and measuring their effectiveness should be priorities to incentive the population to take a more active role. However, tailored educational programs, including booklets and seminars, could be beneficial in improving self-risk assessment of poultry workers.

Though AI epidemic has not caused public panic yet, but the knowledge of respondents regarding AI is not optimistic. This study investigated the levels of knowledge, attitude and practices regarding risk factors and could provide scientific support to assist the Bangladesh government in developing strategies and health education campaigns to prevent transmission of the AI virus among the general population. These campaigns should include such advice as avoidance of direct contact with sick or dead poultry, and use of protective equipment such as gloves and masks when contact is unavoidable. Such campaigns should utilize mass media as the primary medium of dissemination in all localities, with vet personnel being the secondary source, and local opinion leaders, such as family/neighbor taking a significant role in rural areas.

\section{REFERENCES}

1. Abbate R, Di Giuseppe G, Marinelli P and Angelillo IF (2006). Knowledge, attitudes, and practices of avian influenza, poultry workers, Italy. Emerging Infectious Diseases 12: 1762-1765. 


\section{S. K. Sarker and others}

2. Echeverry DM and Rodas JD (2011). Influenza virus A H5N1 and H1N1: features and zoonotic potential. Revista Colombiana de Ciencias Pecuarias 24: 634-646.

3. Fatiregun AA and Saani MM (2008). Knowledge, attitudes and compliance of poultry workers with preventive measures for avian influenza in Lagelu, Oyo State, Nigeria. The Journal of Infection in Developing Countries 2: 130-134.

4. Fielding R, Lam W, Ho E, Lam TH, Hedley AJ and Leung GM (2005). Avian influenza risk perception, Hong Kong. Emerging Infectious Diseases 11: 677-682.

5. Giuseppe GD, Abbate R, Albano L, Marinelli P and Angelillo IF (2008). A survey of knowledge, attitudes and practices towards avian influenza in an adult population of Italy. BMC Infectious Diseases 8: 36.

6. Ismail NA and Ahmed H (2010). Knowledge, attitudes and practices related to Avian Influenza among a rural community in Egypt. Journal of the Egyptian Public Health Association 85: 73-96.

7. Leslie T, Billaud J, Mofleh J, Mustafa L and Yingst S (2008). Knowledge, attitudes, and practices regarding avian influenza (H5N1), Afghanistan. Emerging Infectious Diseases 14: 1459-1461.

8. Najimi A and Golshiri P (2013). Knowledge, beliefs and preventive behaviors regarding Influenza A in students: a test of the health belief model. Journal of Education and Health Promotion 2: 23.

9. OIE (2013a). Questions and answers about influenza A (H7N9): World Organization for Animal Health.

10. OIE (2013b). Update on highly pathogenic avian influenza in animals (Type H5 and H7). World Organization for Animal Health Report No. 43.

11. Paudel M, Acharya B and Adhikari M (2013). Social determinants that lead to poor knowledge about, and inappropriate precautionary practices towards, avian influenza among butchers in Kathmandu, Nepal. Infectious Diseases of Poverty 2: 1.

12. Sarker S, Talukder S, Chowdhury E and Das P (2009). Isolation and Identification of Bacteria from the Workers of Live Bird Markets at Mymensingh, Bangladesh. Journal of Bio-Science 17: 135-138.

13. Sultana R, Rimi NA, Azad S, Islam MS, Khan MSU, Gurley ES, Nahar N and Luby SP (2011). Bangladeshi backyard poultry raisers' perceptions and practices related to zoonotic transmission of avian influenza. The Journal of Infection in Developing Countries 6: 156-165.

14. Thomas JK and Noppenberger J (2007). Avian influenza: a review. American Journal of Health-System Pharmacy 64: $149-165$.

15. WHO (2013). Cumulative number of confirmed human cases for avian influenza A (H5N1). World Health Organization: $1-2$.

16. WHO (2015). Influenza at the human-animal interface: World Health Organization.

17. Xiang N, Shi Y, Wu J, Zhang S, Ye M, Peng Z, Zhou L, Zhou H, Liao Q and Huai Y (2010). Knowledge, attitudes and practices (KAP) relating to avian influenza in urban and rural areas of China. BMC Infectious Diseases 10: 1. 